\title{
Las aproximaciones organizacionales Caracterización, objeto y problemática
}

\author{
Marcela Rendón Cobián y Luis Montaño Hirose
}

\begin{abstract}
Resumen
En este artículo se presenta una visión global y sintética de las diferentes perspectivas de los estudios de la organización. La evolución de estos estudios sigue de alguna manera la dinámica de cambio de las organizaciones y sus contextos, aunque la reflexión permanecería incompleta si no se incorporaran también la evolución de las herramientas metodológicas y la misma reflexión teórica. En este sentido, se destaca el conjunto de disciplinas que concurren a la explicación del fenómeno organizacional, observándose en la actualidad una mayor incorporación del pensamiento social crítico, de la filosofía, la lingüística y la antropología, lo cual deriva en el desdibujamiento del paradigma positivista para dar lugar a una explicación de tipo constructivista que enfatiza el uso de metodologías de tipo cualitativo. Así, la racionalidad abre paso a la vida simbólica, la funcionalidad a las relaciones de poder y, entre otros, la comunicación a la ambigüedad.
\end{abstract}

Palabras clave: estudios organizacionales, evolución, organización, paradigma.

\section{Introducción}

El objetivo del presente ensayo es realizar una reflexión general sobre las principales modalidades del estudio de las organizaciones, destacando las diferentes aproximaciones teóricas que han imperado en más de un siglo. En un primer momento, se enfatizarán diversos aspectos tales como su inscripción espacio-temporal, la problemática abordada, su ubicación paradigmática y su orientación metodológica. En un segundo apartado, desarrollamos la problemática correspondiente al objeto, resaltando los distintos recortes realizados a la organización, que van desde el grupo hasta las redes, desde la tarea pasando por la estructura - hasta el poder, retomando también diversos procesos tales como la decisión, la cultura y el poder. Finalmente, en el tercer apartado realizamos un ejercicio para introducir la idea de cambio paradigmático, representado principalmente por las corrientes posmodernas para intentar construir un esquema de las principales preocupaciones recientes de los estudios organizacionales. Si bien cada uno de estos apartados ameritaría un mayor desarrollo, es importante señalar que en este trabajo se pretende aportar una visión de conjunto que le permita al lector contar con un panorama amplio del estudio teórico de las organizaciones.

\footnotetext{
* Profesores-investigadores del Área de Organización y Sociedad de la Universidad Autónoma Metropolitana, Unidad Iztalapa. Correo electrónico: 1mh@hotmail.com
} 


\section{Corrientes en el estudio de las organizaciones}

El estudio de las organizaciones ha conocido una evolución sorprendente desde finales del siglo XIX y diversas modalidades de aproximación teórica. ${ }^{1} \mathrm{Si}$ bien los orígenes se remontan a finales del siglo XIX, tanto con la escuela sistemática como con la científica, los autores no coinciden plenamente, de acuerdo con las perspectivas desarrolladas, en un solo punto de partida. Así, para la administración lo es generalmente la administración científica, mientras que para la teoría de la organización lo es a veces también ésta, aunque en otras ocasiones lo son las relaciones humanas y en otras más la burocracia. Las aproximaciones sociológicas reconocen más su inicio con esta última debido a la importancia de la obra de Weber. El análisis institucional, por su parte, considera normalmente su inicio con los trabajos de Lapassade y Lourau, de origen sicosocial y sicoanalítico, mientras que el análisis organizacional es frecuentemente interpretado como una modalidad que asume la sociología de las organizaciones, donde Friedberg sería representante de la primera y Crozier de la segunda. Los estudios organizacionales, finalmente, coinciden en retomar sus inicios desde la administración científica. A continuación analizamos, de manera breve, cada una de estas perspectivas (ver cuadro 1).

\footnotetext{
${ }^{1}$ En este trabajo hemos identificado ocho diferentes aproximaciones teóricas para el estudio de las organizaciones: a) administración, b) teoría de la organización, c) análisis institucional, d) sociología del trabajo, e) sociología de las organizaciones, f) análisis organizacional, g) sociología de la empresa y h) estudios organizacionales.
} 


\section{a.1) Administración}

Es de origen netamente estadounidense y, de acuerdo con Chandler, nace con la gran empresa, principalmente la ferrocarrilera. Dado el tipo de problemas que enfrenta esta disciplina, se caracteriza por un contenido multidisciplinario relativamente alto, aunque poco integrado (Montaño: 1999). Su orientación es básicamente funcional y se basa en modelos normativos - frecuentemente basados en la experiencia.

\section{a.2) Teoría de la organización}

Su origen, como la anterior aproximación, es estadounidense. ${ }^{2}$ Aunque algunos remontan su origen a la administración científica, o incluso a la sistemática; parece recibir tal denominación en el período posterior a la Segunda Guerra Mundial, con los trabajos de Simon, Cyert y March (Bagla-Gökalp). A lo largo del siglo pasado logró constituirse como un campo de conocimiento en sí mismo. Su relación con la administración ha sido cada vez más importante al grado de que se encuentra inscrita en las escuelas de Administración en los Estados Unidos (Pfeffer), lo que ha provocado un reforzamiento en su ubicación paradigmática funcional; sin embargo, las diferencias entre ambos campos persisten debido a que la teoría de las organizaciones contempla un contenido social mucho más amplio.

\section{a.3) Análisis institucional}

Esta corriente es de origen francés; se basa en la rica tradición de análisis sicosocial de ese país. Una de sus preocupaciones fundamentales, desde un inicio, fue el descubrimiento de los elementos inconscientes que subyacen en toda organización y que le impiden, tanto a la organización como al individuo, un desarrollo más armónico y equilibrado. El siconanálisis ha realizado aportaciones fundamentales a esta corriente, de orden crítico, al cuestionar los excesos en los que incurren las organizaciones en su afán de alcanzar la excelencia. Esta aproximación, desafortunadamente, fuera de Francia, es poco conocida y ha permanecido un poco en el anonimato.

\section{a.4) Sociología del trabajo}

Como es bien sabido, esta aproximación conoce un alto grado de institucionalización. Se menciona frecuentemente que su origen es francés (Touraine y Naville, Freedman) aunque otros países se han sumado ampliamente a su desarrollo, incluidos varios latinoamericanos, principalmente México y Brasil. Sus temas de estudio han evolucionado conforme la sociedad se ha transformado. Actualmente, se enfatizan aspectos como el de las consecuencias de la nueva tecnología en el trabajo, la cultura obrera y el género, entre otros.

\footnotetext{
${ }^{2}$ Es importante señalar, sin embargo, la importante contribución que el grupo británico del Instituto Tavistok realizara en una de las escuelas de la teoría de la organización, la de la contingencia, primero en la figura de Woodward y posteriormente en la de Pugh et al.
} 


\section{a.5) Sociología de las organizaciones}

Esta aproximación conoce dos grandes vertientes con un origen común: la herencia weberiana. La primera corresponde a la tradición sociológica estadounidense de la escuela de la burocracia, con Merton y Gouldner como autores representativos; la segunda, más tardía, hace referencia a la tradición francesa, con Crozier a la cabeza. En ambos casos se puede observar una importante inquietud por destacar el tema del poder como elemento explicativo y su insistencia en "corregir" el tipo ideal de la burocracia. Aproximación que se entrecruza con la teoría de la organización, que reclama para sí la versión norteamericana.

\section{a.6) Análisis organizacional}

Como la anterior, esta aproximación no resulta con contornos tan precisos. Acepta, desde nuestro punto de vista, dos acepciones: por un lado, hace referencia a una expresión generalizada, un tanto eclécticamente, que se refiere al estudio general de las organizaciones; por otro, designa también una modalidad particular de la sociología de las organizaciones, encabezada por la propuesta por Friedberg, la cual enfatiza la comprensión de la acción colectiva de autores relativamente autónomos, es decir, la organización como proceso. Algunos autores la consideran simplemente como una modalidad de la sociología de las organizaciones.

\section{a.7) Sociología de la empresa}

Si bien la escuela, la familia y el ejército, o aspectos como el trabajo, el poder y la cultura, habían sido estudiados desde una perspectiva sociológica, autores como Bernoux estiman que es tiempo, por su importancia en el conjunto social, de estudiar desde esta perspectiva a la empresa. Esta idea, propuesta originalmente por Sainsaulieu y Segrestin, no ha logrado todavía un reconocimiento amplio dado lo reciente de la propuesta. Es importante notar, por otra parte, que la sociología de las organizaciones dirigió sus esfuerzos principalmente al estudio de las instancias de la administración pública, dejando desatendidas a las empresas que lograron con el tiempo un lugar importante en el concierto de los actores sociales. Por su carácter de campo emergente de conocimiento hace referencias constantes tanto a la sociología de las organizaciones como a la teoría de la organización.

\section{a.8) Estudios organizacionales}

Originada por un grupo de estudiosos europeos, encabezada en un principio por sociólogos ingleses, esta corriente incorpora aspectos como la cultura nacional en su análisis. Retoma el poder, realizando una nueva lectura de Weber e intenta equilibrar la hegemonía estadounidense de la teoría de la organización. Es el grupo más sensible a los planteamientos posmodernos y han establecido un intenso debate alrededor de la discusión paradigmática con la teoría de la organización. Mantienen escasa relación con la administración —sobre todo en el orden normativo- e incorporan algunos elementos provenientes de la sociología del trabajo y de las organizaciones. 


\section{b) Objeto de estudio de los estudios organizacionales}

Todo campo de conocimiento se organiza en torno a un objeto real -las organizaciones, por ejemplo- que debe diferenciarse del objeto de estudio (Audet, Friedberg) en al menos dos sentidos. El primero de ellos reside en la posibilidad de lograr un conocimiento verdadero o simplemente una representación de dicha realidad. Desde nuestro punto de vista, el objeto es simplemente reconstruido, artificialmente, mediante un conjunto de dispositivos metodológicos. El segundo, por su parte, hace referencia a los diversos recortes que se pueden realizar de ese objeto real, privilegiando algunos de sus aspectos, como la toma de decisiones, la cooperación, la estructura informal y muchos otros. Se discute la posibilidad de una comprensión total del fenómeno y se avanza la idea de verosimilitud o de representación parcial de dicha realidad.

El objeto real, a su vez, puede asumir dos posiciones ontológicas, tal como lo plantean Burrell y Morgan, externo o interno a la conciencia del hombre; es decir, su existencia es real por pensarlo el hombre o éste es independiente de su pensamiento. Por otra parte, el objeto de estudio es siempre una construcción. La confusión entre ambos tipos de objeto, o la aceptación de una coincidencia total, proviene - de acuerdo con Audet- de una perspectiva positivista que enfatiza la observación como forma de acceso al conocimiento: el objeto existe por su comprobación empírica.

Entendido de esta manera, el objeto de estudio es un dispositivo del investigador, semejante a un tipo-ideal weberiano, que no corresponde fielmente con la realidad (como solía decir Weber: "no es una construcción social sino sociológica"). Esta construcción puede efectuarse tomando en cuenta el núcleo del objeto real - la organización- - y extenderse en ambos sentidos; es decir, ir desde el pequeño grupo hasta la red interorganizacional o puede, por otro lado, abordarse un proceso o estructura particulares - tales como la toma de decisiones o la estructura informal-y puede ser acotado en el tiempo y en el espacio, por ejemplo, la sucesión en la pequeña empresa familiar en México en la década de los años noventa del siglo XIX.

Ello nos lleva a la noción de recorte del objeto de estudio, implícita en todo proceso de construcción de dicho objeto. Así, en el planteamiento de la teoría de la organización -o de los estudios organizacionales, de acuerdo con nuestros planteamientos anteriores-, en su vertiente más funcionalista, podemos observar diversos recortes a la realidad organizacional en términos de los planteamientos centrales realizados (ver cuadro 2). 
Por otro lado, es importante señalar que el campo de estudio no se deriva exclusivamente de la voluntad del investigador porque el recorte está, de alguna manera, influido por la etapa histórica en la que se inscribe una problemática particular de las organizaciones, el desarrollo específico de las herramientas metodológicas, la visión teórica determinada y las modalidades de relaciones sociales representativas del momento.

El objeto de estudio de los estudios organizacionales ha conocido una transformación radical a partir de finales de los setenta del siglo pasado. En efecto, la conformación de un nuevo paradigma, que no ha alcanzado todavía el nivel de estructuración del anterior, no proporciona el mismo nivel de comprensión no sólo por su nivel actual de desarrollo sino también por las implicaciones teóricas que en él se manejan. Una de estas implicaciones significativas está en la enorme distancia que pretende establecer con el pensamiento moderno; el posmodernismo requiere de estructuras de pensamiento distintas, con un alto nivel de ambigüedad. Ejemplo de ello es la construcción teórica realizada bajo esquemas de tipo binario y precisión conceptual que han caracterizado al modernismo. La menor claridad conceptual del posmodernismo, en tanto paradigma, dificulta el establecimiento de estructuras simples. No obstante lo anterior, puede de cualquier manera establecerse, en términos de ejercicio académico, un esquema analítico para esta segunda etapa de los estudios organizacionales.

\section{c) Mapa conceptual de los estudios organizacionales}

Construir un mapa conceptual de los estudios organizacionales no es tarea fácil dado el carácter relativamente incipiente del proyecto constructivista (Reed), que caracteriza a la segunda etapa de este campo de estudio. El mapa conceptual que proponemos incluye, entonces, dos etapas: la primera abarcaría desde finales del siglo XIX hasta finales de la década de los setenta del siglo pasado (ver lámina I); mientras que la segunda etapa, de acuerdo con el debate acerca de la naturaleza paradigmática de esta aproximación, retomaría desde los años setenta del siglo XX hasta nuestros días (ver lámina II). 
El mapa conceptual de los estudios organizacionales —en su primera etapa- está representado en el cuadro 2, que comparte con la teoría de la organización, en el que se muestra con claridad sus planteamientos centrales, los recortes realizados al objeto, las estrategias disciplinarias más relevantes y los principales dispositivos metodológicos empleados. En esta nueva etapa, correspondiente a la década de los setenta en adelante, podemos detectar cuatro grandes temas y nuevas disciplinas que apoyan su desarrollo.

Éstos representan grandes preocupaciones teóricas y de campo que han involucrado a los grupos de académicos en su discusión y desarrollo; éstos son los correspondientes a los de ambigüedad, poder, cultura y, más recientemente, el de paradigma. Cada uno de ellos se encuentra más apoyado por campos disciplinares distintos, la lingüística, la filosofía política, la antropología y la filosofía de las ciencias, enmarcadas todas ellas por nuevos desarrollos de la sociología. Veamos a continuación estos aspectos, que constituyen los ejes de conformación de esta nueva etapa.

\section{c.1) La ambigüedad}

Este tema comienza a constituirse de manera temprana, desde la primera época, alrededor de los sesenta. Las anarquías organizadas enfatizan la dificultad de establecer una relación adecuada entre fines y medios debido a que ambos están conformados de manera ambigua y múltiple, y su vinculación es de naturaleza flojamente acoplada. La ambigüedad pone de manifiesto el carácter parcial de la racionalidad como motor de la acción organizada y retoma la importancia del hábito y el símbolo como formas explicativas de la organización moderna. El sentido no es único, como lo demostrarán más adelante los diversos planteamientos provenientes de la lingüística, en especial los estudios referidos a la importancia de la metáfora en la vida organizacional.

\section{c.2.) El poder}

Si bien el poder fue considerado en la primera época, bajo la figura de autoridad y bajo la influencia del paradigma positivista, como una especie de anormalidad, con su concomitante idea de conflicto, en el constructivismo es aceptado que el poder es inherente a toda relación cobijada por un contexto organizacional. El poder se "naturaliza", no es más un objeto extraño; es incorporado, incluso en los planteamientos funcionalistas, como una necesidad del sistema. Los planteamientos de la teoría del proceso laboral, de inspiración marxista, permearon a los estudios organizacionales y diversos análisis fueron recuperados - en la segunda mitad de la década de los setenta y principios de los ochenta- en revistas consideradas tradicionales, como Administrative Science Quarterly que había logrado forjarse una reputación de científica al especializarse en teoría de la contingencia. Este eje se va matizando a lo largo del tiempo; se incorporan los planteamientos de autores tan renombrados como el de Foucault, quien en su libro Vigilar y Castigar expone que el poder no debe asociarse a grandes estrategias ni a grandes personajes, sino a la acción cotidiana de pequeños dispositivos que hacen "invisibles" las manifestaciones de poder y limitan las posibilidades de la resistencia. El inconsciente juega un papel central en el desarrollo de este eje. Los trabajos de Pagès, Enriquez y de Gaulejac, entre otros, ponen de manifiesto las complejas redes discursivas, imperceptibles para la conciencia individual, en las que el sujeto queda atrapado, lo que lo lleva a participar incluso en su propia dominación. 


\section{c.3.) Cultura}

Como los aspectos anteriores, la cultura cuestiona el nivel de racionalidad presumible en los actores sociales. Constituía un concepto que se aplicaba a las sociedades tradicionales, llamadas incluso primitivas, no para explicar su supuesto atraso, sino para asomarse a $-\mathrm{y}$ asombrarse con- un mundo mágico, repleto de símbolos. El estadio primitivo era simbólico; el moderno, supuestamente racional. Este planteamiento se viene abajo con la consideración de que toda organización se ve afectada por la cultura. Si bien la cultura refiere a la vida simbólica comunitaria, en términos amplios, la expresión metafórica de cultura organizacional moviliza una serie de recursos para adentrarse en los aspectos ocultos de la funcionalidad, principalmente empresarial. Tal es el esfuerzo pionero de Hofstede, quien analiza el caso de la IBM implantada en varios países del mundo. Esfuerzos posteriores, de carácter más cualitativo, se han venido realizando desde entonces, destacándose los trabajos de Alvesson y de d'Iribarne.

\section{c.4.) Paradigma}

Este aspecto es de aparición más reciente y constituye en la actualidad un debate intenso. Inspirados en el trabajo pionero de Burrell y Morgan, el debate sobre el tema de la inconmensurabilidad de Khun constituye un punto de encuentro de los estudios organizacionales en la época actual. De acuerdo con estos autores, el estudio de las organizaciones puede realizarse a partir de dos ejes. El primero, horizontal, tiene que ver con el carácter objetivo o subjetivo con que se realiza la aproximación; mientras que el segundo, vertical, hace alusión a si el análisis se realiza desde una perspectiva de cambio o de regulación social. Así, los autores establecen la existencia de cuatro paradigmas principales: 1) el paradigma funcionalista, caracterizado por sus explicaciones acerca del estatus, orden social, consenso, integración social, solidaridad y satisfacción de necesidades; enfatiza las explicaciones de tipo racional; es altamente pragmático, es decir, se interesa por generar conocimiento que pueda ser fácilmente utilizado; se orienta más a proporcionar soluciones prácticas que al descubrimiento de problemas. 2) El paradigma interpretativo plantea que el mundo de los asuntos humanos está basado en la cohesión; es integrado y ordenado; los problemas de conflicto, dominación, contradicción y cambio, no forman parte de su repertorio teórico; ha habido pocos intentos por estudiar conceptos y situaciones organizacionales desde este punto de vista; este paradigma no ha realizado aportes significativos, de acuerdo con Burrell y Morgan, al estudio de las organizaciones. 3) El paradigma humanista-radical se define por su relación con el desarrollo de una sociología de cambio radical desde el punto de vista subjetivo; establece un mayor énfasis en el cambio social, en los modos de dominación y en la búsqueda de la emancipación; esta perspectiva enfatiza más la conciencia humana y representa el punto más alejado del estructural funcionalista. 4) Finalmente, el paradigma estructuralista radical se inspira en una sociología del cambio radical, pero desde la perspectiva objetiva; enfatiza también el conflicto estructural, los modos de dominación y la contradicción; común a los teóricos que se inscriben en este paradigma es la visión de que la sociedad contemporánea está caracterizada por conflictos fundamentales, los cuales generan un cambio radical a través de crisis políticas y económicas. Estos cuatro paradigmas nos permiten hacer el ejercicio para ubicar las ocho aproximaciones al estudio de las organizaciones (ver Lámina III). 


\section{d) Conclusiones}

Numerosas corrientes han ido construyendo, a lo largo de poco más de un siglo de historia, el campo de estudio de las organizaciones; ellas varían en función del enfoque paradigmático en el que se ubican y promueven, el cual a su vez depende de la perspectiva del mundo del que parten y de los recortes que realizan al objeto de estudio. Todas ellas permanecen vigentes en nuestros días al constituir grupos académicos que sustentan y avanzan en direcciones particulares; algunas son más explicativas, mientras que otras están encaminadas por resolver problemas prácticos; unas son más generales, otras más específicas; unas promueven cambios sociales radicales, en cambio otras apuestan a una evolución más lenta; unas comienzan su análisis a partir de las estructuras y otras observan primero al sujeto; sujeto, por cierto, a veces dotado de una gran capacidad de entender racionalmente su entorno y apegar sus pautas de comportamiento a dicho esquema; sujeto, en otras ocasiones, atrapado en una vorágine de redes semánticas que lo atrapan irremisiblemente en una vida simbólica de la que no puede librarse ni explicarse totalmente. Cada una de estas aproximaciones explica y actúa de manera diferente sobre el mundo; cada una propone su concepto de organización y, por lo tanto, de hombre. La naturaleza misma de cada uno de estos diversos planteamientos promueve en el investigador una serie de preguntas particulares y prefigura un mundo posible de respuestas y la manera de proceder a su encuentro.

Los deslindes paradigmáticos obedecen no sólo a cuestiones de carácter académico, sino que en ellos subyacen aspectos de tipo social como la búsqueda del prestigio e intereses grupales, tal como acontece — por ejemplo_ en los "enfrentamientos" entre la teoría de la organización, la administración y los estudios organizacionales, o el poco reconocimiento que ha recibido, hasta el momento, el análisis institucional. La inconmensurabilidad kuhniana no es tan sólo una cuestión intelectual sino social, en su sentido más amplio: la construcción del conocimiento implica también relaciones simbólicas, culturales y de poder. La falta de comunicación no se debe exclusivamente a razones de tipo teóricometodológico sino también a la dinámica social misma de los grupos de investigación. La imposición de un paradigma sobre los otros, de una corriente explicativa sobre las demás, traería como consecuencia no un mayor acercamiento a la verdad y mejores organizaciones para la sociedad, sino que representaría un triunfo político de un grupo sobre el resto de los demás.

Visto desde otro ángulo, la inconmensurabilidad significa, al menos en cierta medida, la incapacidad de asumir criterios más académicos en la búsqueda incesante, e inalcanzable, de la verdad. El diálogo constituye entonces, desde nuestro punto de vista, una de las vías más promisorias no para unificar el pensamiento - lo que nos llevaría a una especie de totalitarismo intelectual - sino para emprender un intercambio más fructífero; no para afianzar nuestras seguridades sino para, a partir de la duda y la auto-crítica, elevar nuestro nivel de reflexión; no sólo para ser más tolerantes, sino para ver aquello que todavía nos permanece oculto; no sólo para incrementar nuestra tolerancia, en una especie de democracia académica, sino para lograr una mejor comprensión de nuestra propia realidad. Así, por ejemplo, pensamos que es necesario ampliar y profundizar los intercambios entre estudios organizacionales y administración con el fin de lograr una mejor comprensión de nuestra realidad organizacional y una mayor capacidad de ingerencia en ella. Las diversas 
aproximaciones organizacionales no deben perseguir una verdad absoluta y contundente que excluya al resto de las propuestas sino, por el contrario, dialogar entre ellas sobre sus propias posibilidades y limitaciones.

El interés en el estudio de las organizaciones se ha extendido a una amplia gama: universidades, pequeña empresa, hospitales, municipios, prisiones, organizaciones no gubernamentales, entre otras. Es necesario, por lo tanto, reconocer también la naturaleza y dinámica diversas de estos espacios institucionales y no pretender realizar generalizaciones explicativas que limitan las posibilidades de reconocimiento de prácticas particulares.

El avance del estudio de las organizaciones reside precisamente en el reconocimiento de las particularidades institucionales, culturales, etcétera, que delimitan y orientan nuestra mirada analítica. El intercambio sobre aspectos de orden más general y comparativo debe seguir incrementándose, por otra parte, con la comunidad internacional, no para incorporar ciegamente dichos planteamientos, sino para elevar nuestro nivel de comprensión. En este debate internacional participan actualmente no sólo los países precursores, tanto estadounidenses como europeos, sino también algunos países latinoamericanos, cuya contribución, aunque modesta, se está dando de manera decisiva.

\section{e) Bibliografía}

La bibliografía acumulada en las diversas aproximaciones para el estudio de las organizaciones es extremadamente amplia. Sin duda, la importancia creciente de este tipo de trabajos refleja su alta relevancia para la comprensión y reorientación de diversos aspectos de la vida social organizada. Hemos incluido en este apartado, a título indicativo, sólo aquella que se destaca más por su pertinencia en el desarrollo de nuestro trabajo.

\section{Bibliografía}

Alvesson Matt y Per Berg (1992), Corporate Culture and Organizational Symbolism. An Overview, Walter de Gruyter, Berlín.

Aubert Nicole y Vincent de Gaulejac (1991), Le coût de l'excellence, Éditions du Seuil, París.

Audet, Michel (1986), "Le procès des connaissances de l'administration", en Audet, Michel y Jean-Louis Malouin (eds.) (1986), La production des connaissances scientifiques de l'Administration, Les Presses de l'Université Laval, Quebec, pp. 2356.

Bagla-Gökalp (1998), Sociologie des organisations, La découverte, París.

Barba Álvarez, Antonio y Pedro C. Solís Pérez (1997), Cultura en las organizaciones. Enfoques y metáforas en los estudios organizacionales, Editorial Vertiente, México. 
Ballé, Catherine (1990), Sociologie des organizations, Presses Universitaires de France, París.

Bernoux, Philippe (1995), La sociologie des enterprises, Éditions du Seuil, París.

Burrell G. y G. Morgan (1979), Sociological Paradigms and Organizational Analisis, Gower, Aldershot.

Chandler, Alfred (1962), Strategy and Structure, MIT Press, Cambridge.

Clarke, Thomas y Stewart Clegg ( 1998), Changing Paradigms. The transformation of management knowledge for the 21st century, Harper Collins, Londres.

Clegg, Stewart R., Cynthia Hardy y Walter R. Nord (eds.) (1996), Handbook of Organization Studies, Sage, Londres.

Crozier, Michel (1963), Le phénomène bureaucratique, París, Éditions du Seuil.

Cyert, R. M. y March, James (1963), A Behavioral Theory of the Firm, Englenwood Cliffs, Prentice-Hall, Nueva Jersey.

Donaldson, Lex (1985), In defence of organization theory: a response to the critics, Cambridge University Press, Cambridge.

Hatch, Mary Jo (1997), Modern, Symbolic and Postmodern Perspectives, Oxford University Press, Nueva York.

Enriquez, Eugène (1992), L'organisation en analyse, Presses Universitaires de Frances, París.

Enriquez, Eugène (1997), Les jeux du pouvoir et du désir dans l'entreprise. Desclée de Brouwer, París.

Friedberg, Erhard (1997), Le pouvior et la règle. Dynamique de l'action organisée, Éditions du Seuil, París.

Friedmann, Georges y Pierre Naville (comps.) (1963), Tratado de sociología del trabajo, Fondo de Cultura Económica, México.

Gergen, Kennet y Tojo Joseph Tatcherkery (1996), "Organizational Science as Social Construction: Postmodern Potentials", en The Journal of Applied Behavioral Science, 32/4, pp. 356-377.

Hassard, John (1993), Sociology and organization theory. Positivism, paradigms and postmodernity, Cambridge University Press, Cambridge. 
Lapassade, George (1967), Groupes, organizations et institutions, Gauthier-Villars, París.

Mintzberg, Henry (1983), Structure in Five: Designing in Fives: Designing Effective Organizations, Engleewood Cliffs, Prentice-Hall, Nueva Jersey.

Montaño Hirose, Luis (1999), "La investigación en Administración. Reflexiones para el caso de México", en Administración y organizaciones, $\mathrm{n}^{\circ}$ 2, Universidad Autónoma Metropolitana-Xochimilco, pp. 7-20.

(2004), "El estudio de las organizaciones en México. Una perspectiva social", en Luis Montaño Hirose (coord.), Los estudios organizacionales en México, Universidad Autónoma Metropolitana, Miguel Angel Porrúa y Universidad de Occidente, México (en prensa).

y Marcela Rendón Cobián (2000), "La noción de organización. Sentido, polisemia y construcción social", en Iztapalapa, $\mathrm{n}^{\circ} 48$, Universidad Autónoma Metrolpolitana-Iztapalapa.

Mouzelis, Nicos (1968), Organisation and Bureaucracy. An Analysis of Modern Theories, Alding Publishing, Chicago.

Pagès, Max, Michel Bonetti, Vincent de Gaulejac y Daniel Descendre (1979), L'emprise de l'organisation, Presses Universitaires de France, París.

Pfeffer, Jeffrey (1997), Nuevos rumbos en la Teoría de la Organización: Problemas y posibilidades, Oxford University Press, México.

Pugh, Derek S. (1963), "A Conceptual Scheme for Organizational Analysis", en Administrative Science Quarterly, vol. 8, pp. 289-315.

Sainsaulieu, Renaud (coord.) (1990), L'entreprise, une affaire de société, Presses de la Fondation Nationale des Sciences Politiques, París, pp. 31-45.

Segrestin, Denis (1992), Sociologie de l'entreprise, Armind-Colin, París.

Scott, W. R. (1981), Organizations: Rational, Natural and Open Systems, Prentice-Hall, Nueva Jersey.

Simon, Herbert A. (1984), El comportamiento administrativo: estudio de los procesos decisorios en la organización administrativa, Aguilar, Buenos Aires.

Weber, Max (1970), Economía y sociedad, Fondo de Cultura Económica, México.

Woodward, Joan (1958), Management and Technology, HMSO, Londres. 


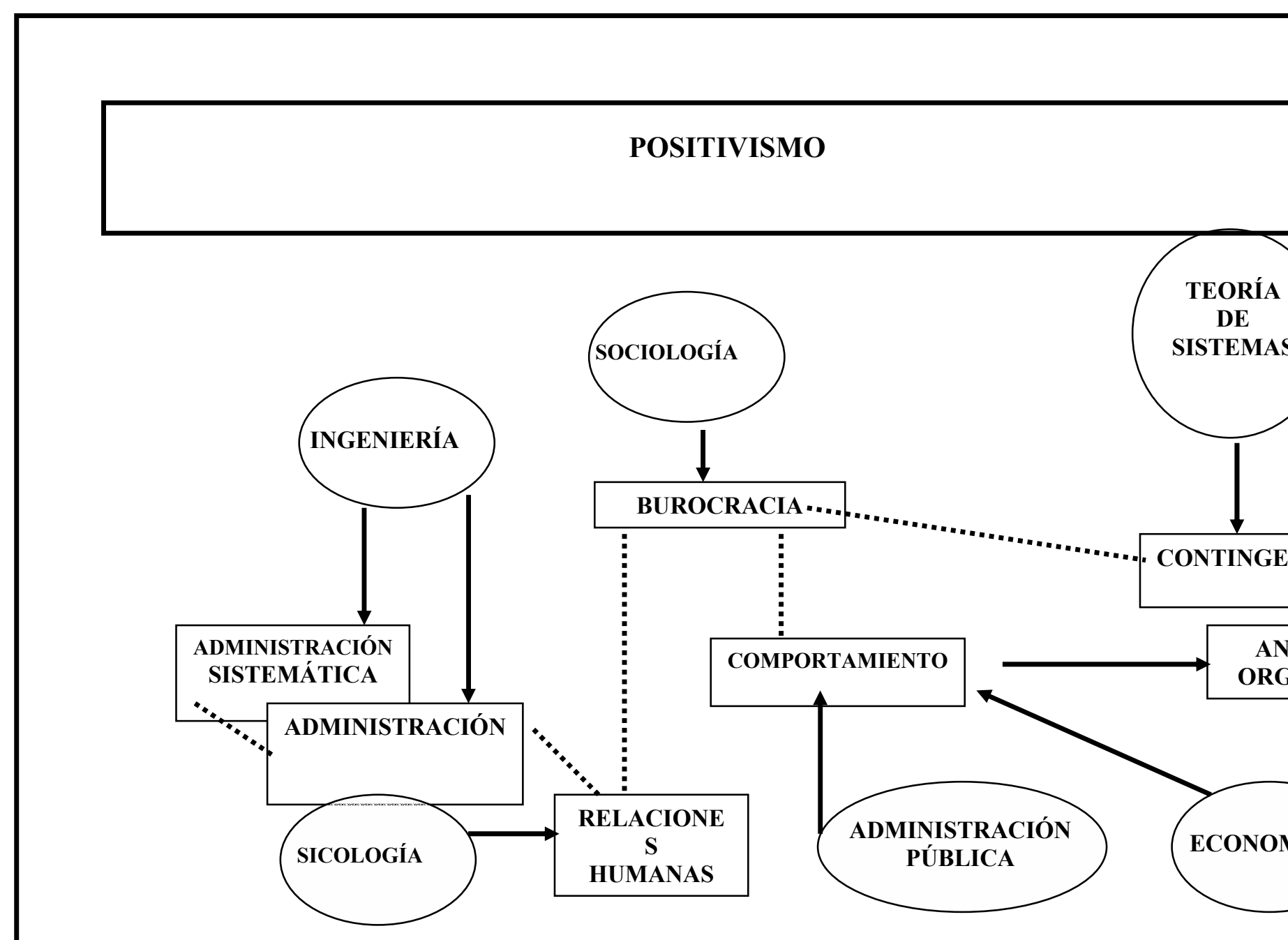




\section{CONSTRUCTIVISMO}

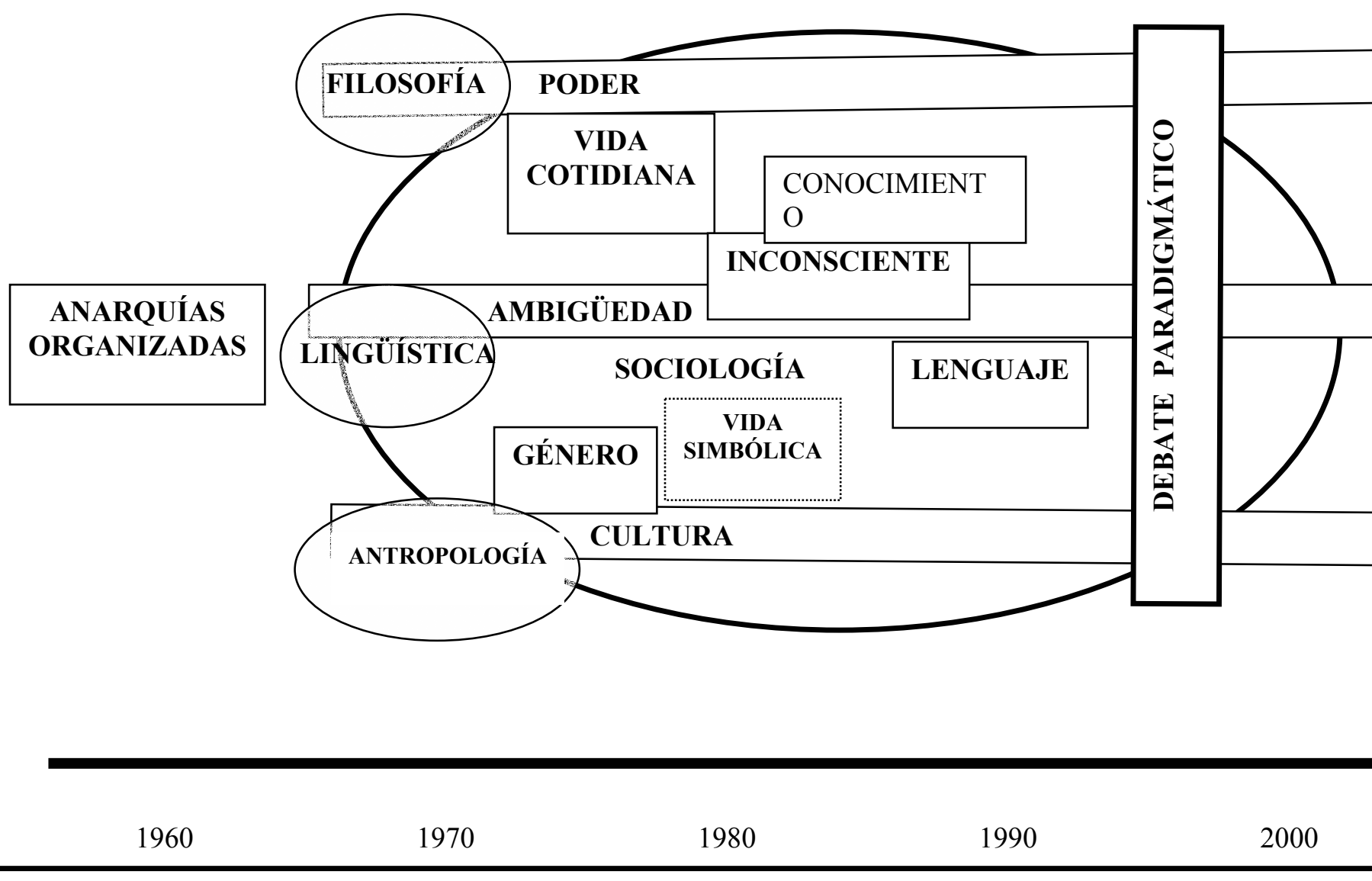




\section{Cambio}

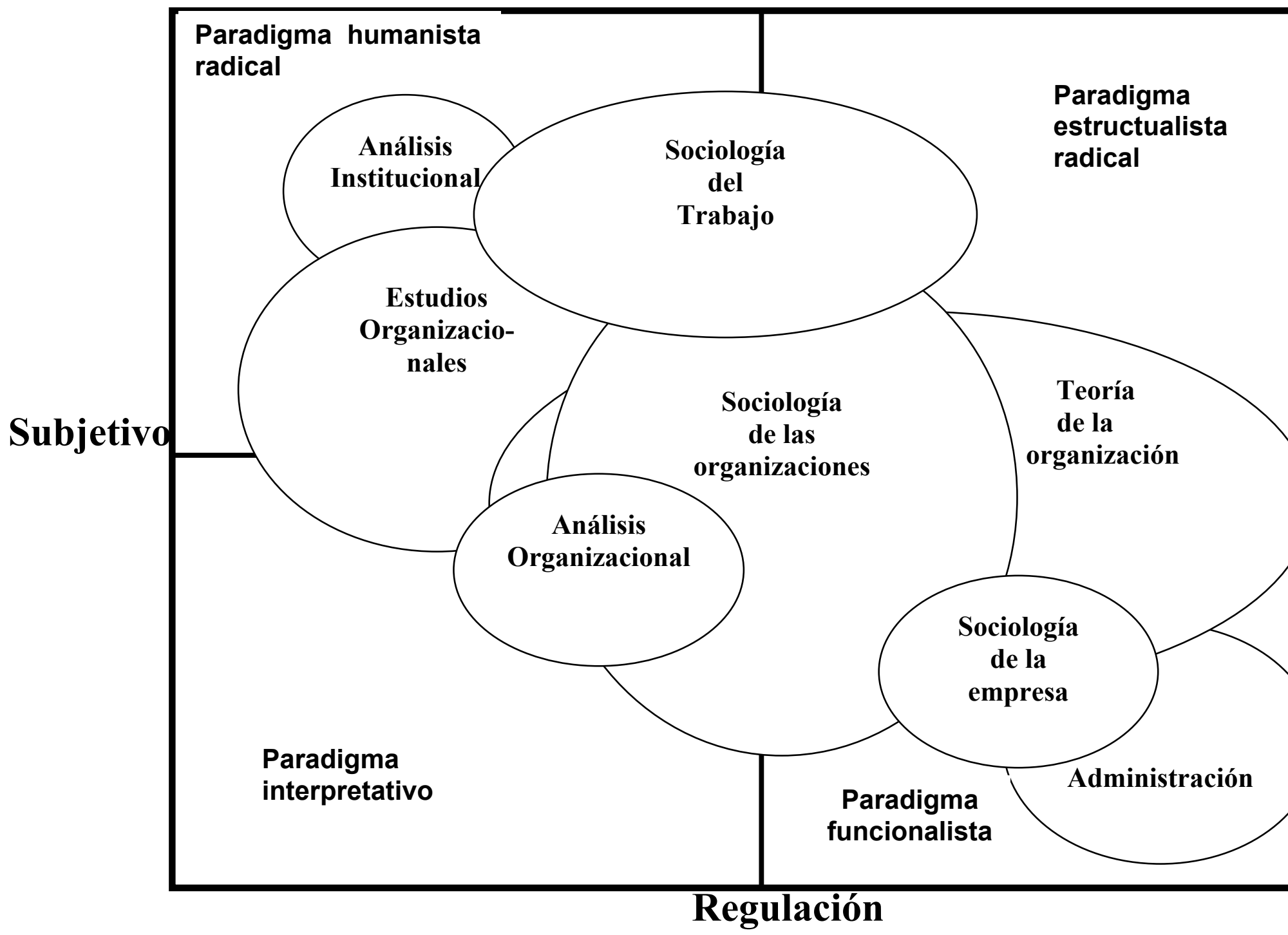

